\title{
What Elements of the Inflammatory System Are Necessary for Epileptogenesis In Vitro ${ }^{1,2}$
}

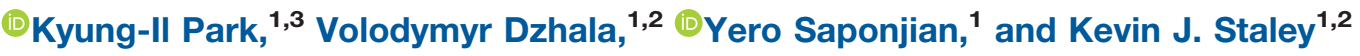

\section{DOI:http://dx.doi.org/10.1523/ENEURO.0027-14.2015}

${ }^{1}$ Department of Neurology, Massachusetts General Hospital, Boston, Massachusetts 02129, ${ }^{2}$ Harvard Medical School, Boston, Massachusetts 02129, and ${ }^{3}$ Seoul Paik Hospital, Inje University, Seoul 100-032, South Korea

\begin{abstract}
Epileptogenesis in vivo can be altered by manipulation of molecules such as cytokines and complement that subserve intercellular signaling in both the inflammatory and central nervous systems. Because of the dual roles of these signaling molecules, it has been difficult to precisely define the role of systemic inflammation in epileptogenesis. Organotypic hippocampal brain slices can be maintained in culture independently of the systemic inflammatory system, and the rapid course of epileptogenesis in these cultures supports the idea that inflammation is not necessary for epilepsy. However, this preparation still retains key cellular inflammatory mediators. Here, we found that rodent hippocampal organotypic slice cultures depleted of $\mathrm{T}$ lymphocytes and microglia developed epileptic activity at essentially the same rate and to similar degrees of severity as matched control slice cultures. These data support the idea that although the inflammatory system, neurons, and glia share key intercellular signaling molecules, neither systemic nor CNS-specific cellular elements of the immune and inflammatory systems are necessary components of epileptogenesis.
\end{abstract}

Key words: epileptogenesis; immune system; inflammatory; microglia

\section{Significance Statement}

The inflammatory and central nervous systems share many signaling molecules, compromising the utility of traditional pharmacological and knockout approaches in defining the role of inflammation in CNS disorders such as epilepsy. In an in vitro model of post-traumatic epileptogenesis, the development of epilepsy proceeded in the absence of the systemic inflammatory system, and was unaffected by removal of cellular mediators of inflammation, including macrophages and T-lymphocytes. These results are not meant to disprove the idea that "inflammation causes epilepsy", but rather circumscribe the overlap between the inflammatory system versus the CNS mechanisms that are operative during post-traumatic epileptogenesis.

\section{Introduction}

Local and systemic inflammation may play a role in epileptogenesis (Vezzani et al., 2012). The brain is largely

Received September 15, 2014; accepted February 27, 2015; First published March 3, 2015.

${ }^{1}$ The authors declare no competing financial interests.

${ }^{2}$ Author contributions: K.J.S. designed research; K.-I.P. and Y.S. performed research; V.D. analyzed data; K.-I.P. and K.J.S. wrote the paper.

This study was supported by NIH Grants R21 NS072258 and R01 NS077908 (NINDS), and the Inje Research and Scholarship Foundation 2013 (KI Park). We thank Ji Young Lee, MD PhD for review of the manuscript. shielded from the systemic immune system by the blood- brain barrier (Lampron et al., 2013), but an active innate immune system converges to activate phagocytic final effectors, the microglia. These cells comprise $10 \%$ of the

Correspondence should be addressed to Dr. Kevin J. Staley, MGH Neurology, CNY-114, Room 2600, $11416^{\text {th }}$ Street, Charlestown, MA 02129. E-mail: Staley.Kevin@mgh.harvard.edu

DOI:http://dx.doi.org/10.1523/ENEURO.0027-14.2015

Copyright (C) 2015 Park et al.

This is an open-access article distributed under the terms of the Creative Commons Attribution 4.0 International, which permits unrestricted use, distribution and reproduction in any medium provided that the original work is properly attributed. 
cells in the brain (Benarroch, 2013), where lymphocytes are also present (Ravizza et al., 2008).

There is robust pathological evidence for the involvement of cellular elements of the immune and inflammatory systems, including $T$ lymphocytes and microglia, in epilepsy syndromes such as Rassmussen's encephalitis (Bien et al., 2002; Granata and Andermann, 2013). Other epilepsy syndromes are driven by humoral elements of the immune system, including antibodies to NMDA receptors and other neuronal proteins (Davis and Dalmau, 2013; Gresa-Arribas et al., 2014). Inflammatory mediators, including the cytokines interleukin (IL)- 6 and IL- $1 \beta$, complement cascade factor $\mathrm{C} 1 \mathrm{q}$, transforming growth factor (TGF)- $\beta$, and tumor necrosis factor alpha (TNF $\alpha$ ), are upregulated in human epileptic tissue (Vezzani et al., 2012; Liimatainen et al., 2013). These inflammatory mediators are increased experimentally by prolonged seizures (Minami et al., 1991; Vezzani et al., 1999). Manipulation of immune and inflammatory mediators alter seizures. Inhibition of leukocyte infiltration of the blood-brain barrier prevented experimental epilepsy (Fabene et al., 2008), and IL-1 $\beta$ antagonists reduced induced seizures (Librizzi et al., 2012).

The interpretation of these intriguing findings is complicated by two issues. First, these inflammatory mediators also play important roles in physiological synaptic modifications, including those that underlie learning and memory. The cytokines implicated in epilepsy are also produced by neurons and astrocytes in the normal, uninflamed brain (Vitkovic et al., 2000; Yirmiya and Goshen, 2011; Pribiag and Stellwagen, 2014). For example, IL-1 $\beta$ and IL- 6 are increased by synaptic stimuli that induce physiological synaptic plasticity (Schneider et al., 1998; Balschun et al., 2004). Cellular and cytokine elements of the immune and inflammatory systems, including $T$ lymphocytes and IL-1 $\beta$, play essential roles in learning and memory (Schneider et al., 1998; Yirmiya et al., 2002; Kipnis et al., 2004). Homeostatic scaling of synaptic strength entails cytokines including $\mathrm{TNF} \alpha$, and possibly IL-1 $\beta$ (Pribiag and Stellwagen, 2014). Microglia participate in physiological anatomical synaptic alterations (Paolicelli et al., 2011; Schafer et al., 2012). Microglial activation after epileptogenic injuries is complex and not strongly correlated with neuronal loss (Papageorgiou et al. 2014). Kindling studies have not found significant increases in microglia or cytokines (Khurgel et al., 1995; Tooyama et al., 2002; Aalbers et al., 2014), and experimental antiepileptogenic therapies are not associated with changes in microglial activation (van Vliet et al., 2012). Recent studies exploring the expression of cytokines in temporal lobe epilepsy have not found evidence that inflammation is a necessary for element of hippocampal sclerosis (Aalbers et al., 2014).

Second, inflammation and cell loss coexist (Tooyama et al., 2002). The clinical and experimental situations in which the inflammatory system has been implicated in epileptogenesis are also characterized by neuronal death and astrogliosis (Ravizza et al., 2008). Neuronal death and astrogliosis are also epileptogenic (Dudek and Staley,
2012), although it has not been demonstrated whether inflammation and cell loss act independently.

Studying the relation of inflammation and epilepsy by removal of elements of the systemic inflammatory system in vivo is impractical due to ongoing monocytic immigration from the bloodstream (Ransohoff and Cardona, 2010). As a proof-of-concept experiment to test the necessity of the immune and inflammatory systems in epileptogenesis, we used a reduced in vitro system in which the cellular effector elements of these systems can be removed and the effects on epileptogenesis observed. The hippocampal organotypic slice culture is a wellcharacterized in vitro system of epileptogenesis (McBain et al., 1989; Gutnick et al. 1989; Bausch and McNamara, 2000; Dyhrfjeld-Johnsen et al., 2010; Marchi et al., 2011; Berdichevsky et al., 2012, 2013; Ransohoff and Brown, 2012; Albus et al. 2013). Blood vessels are present but the blood-brain barrier is not operative and the systemic immune system is not present. We characterized epileptogenesis in preparations from control and T lymphocytedeficient nude mice, with and without microglial depletion by clodronate (Kohl et al. 2003; Kumamaru et al., 2012).

\section{Materials and Methods}

\section{Culture of organotypic hippocampal slices}

All animal-use protocols were in accordance with the guidelines of the National Institutes of Health and our Institution for Comparative Medicine on the use of laboratory animals, and approved by the Subcommittee on Research and Animal Care. Hippocampal slices were prepared at postnatal days 6-8 from C57BL/6 mice or T lymphocyte-deficient nude mice (Foxn1nu/Foxn1nu, http://jaxmice.jax.org/strain/002019.html) or SpragueDawley rats of either sex. Slices (400 $\mu \mathrm{m}$ thick) from a Mcllwain tissue chopper (Mickle Laboratory Engineering Co.) were mounted in clots of chicken plasma (Cocalico Biologicals) and thrombin (Sigma-Aldrich) on poly-Llysine-coated glass coverslips (Electron Microscopy Sciences). Slices were incubated in roller tubes (Nunc) at $37^{\circ} \mathrm{C}$ within $750 \mu \mathrm{l}$ of NeurobasalA/B27 medium supplemented with $0.5 \mathrm{mM}$ GlutaMAX and $30 \mu \mathrm{g} / \mathrm{ml}$ gentamicin (Invitrogen). This concentration of gentamycin was less than half the lowest concentration demonstrated to induce regenerative activity in vitro (Grøndahl and Langmoen 1993). Culture media were changed biweekly.

\section{Field potential recording}

Extracellular field potentials were recorded in area CA1 or CA3 of hippocampal slices in a conventional submerged chamber using tungsten-coated microelectrodes (diameter, $50 \mu \mathrm{M})$. Oxygenated $\left(95 \% \mathrm{O}_{2}\right.$ and $\left.5 \% \mathrm{CO}_{2}\right)$ artificial CSF containing $126 \mathrm{mM} \mathrm{NaCl}, 3.5 \mathrm{mM} \mathrm{KCl}, 2$

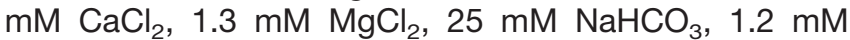
$\mathrm{NaH}_{2} \mathrm{PO}_{4}$, and $11 \mathrm{mM}$ glucose (pH 7.4), were continuously perfused at $33 \pm 0.5^{\circ} \mathrm{C}$. Flow rate was $2.5 \mathrm{ml} / \mathrm{min}$. Before actual recording, slices were allowed to stabilize in the recording chamber for at least $1 \mathrm{~h}$, and then extracellular field potentials were recorded for $1 \mathrm{~h}$ in each slice. pCLAMP 8.2 (Axon Instruments) was used for data acquisition. Recordings were sampled at $10 \mathrm{kHz}$ and filtered 
Table 1. Numbers of slices and animals used in each experiment

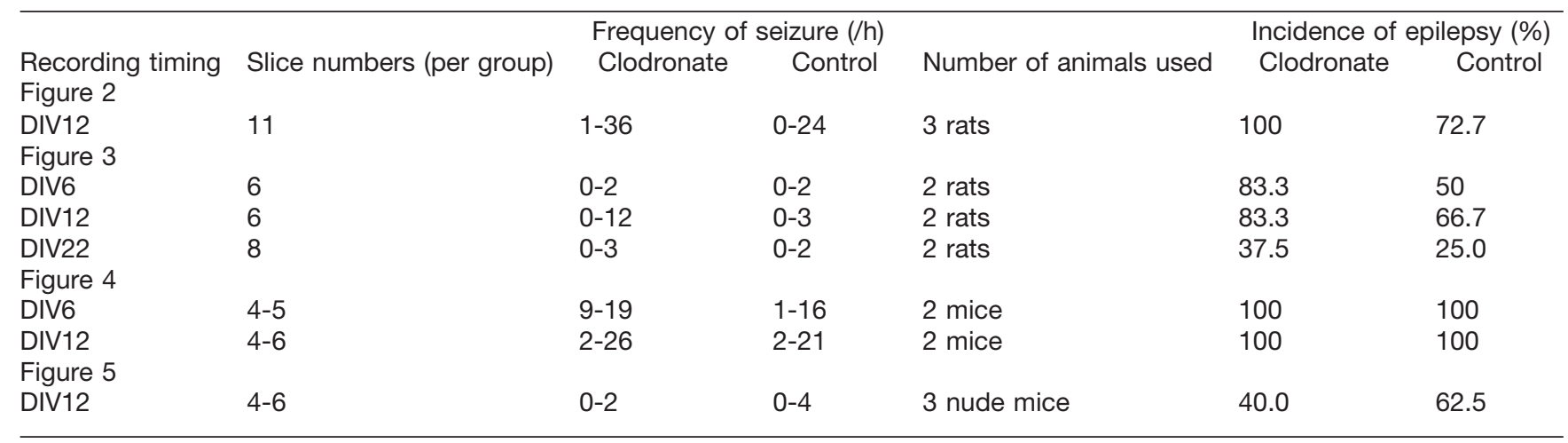

from $1 \mathrm{~Hz}$ to $1 \mathrm{kHz}$. Seizure-like activity (SLA) was defined as high amplitude ( $\times 3$ baseline), high frequency $(>10 \mathrm{~Hz})$ spikes followed by afterdischarges, with the duration of the spike and afterdischarge complex lasting more than 5 s. Incidence of SLA and numbers of slices and animal in the experiment are summarized in Table 1.

\section{Chemical depletion of microglia}

Clodronate is a selective macrophagic and microglial toxin without evidence of injury to other cellular components (Kohl et al. 2003; Kumamaru et al., 2012). Perivascular macrophages could be retained in slice cultures, but these cells are also depleted by clodromate at concentrations below those needed to deplete microglia (Polfliet et al., 2001). To assess whether microglia alter the course of epileptogenesis or ictogenesis, we incubated slice cultures in clodronate-encapsulated liposomes (Clodrosome, purchased at www.clodrosome.com, containing 17 $\mathrm{mM}$ of clodronate disodium salt, $24 \mathrm{mM}$ of phosphatidylcholine, and $11 \mathrm{mM}$ of cholesterol suspended in PBS) for 3-6 d, as specified in the Results (Fig. 4A). During these incubations, Clodrosome was replenished with each media change.

\section{Immunohistochemistry of organotypic hippocampal slices}

Slices were fixed overnight with 4\% paraformaldehyde at room temperature. They were washed with PBS several times and stored in PBS at $4{ }^{\circ} \mathrm{C}$ until use. The hippocampi were scraped out gently from the bottom of petri dishes or coverslips and then treated with $0.5 \%$ Triton X-100 overnight. Blocking was done with $20 \%$ bovine serum albumin (BSA) for $4 \mathrm{~h}$ at room temperature on a shaker. We incubated tissues overnight with the microglial-specific antibody anti-ionic calcium-binding adapter molecule 1 (lba-1, 1:1000; Waco Chemicals), a protein present in both perivascular macrophages and microglia (Sasaki et al. 2001), with/without the neuron-specific antibody anti-NeuN (1:50; Millipore) as primary antibodies. Goat anti-rabbit IgG Alexa 594 (1:200; Invitrogen) with/without goat anti-mouse IgG Alexa 405 (1:200; Invitrogen) were used as secondary antibodies. All antibodies were dissolved in 5\% BSA. DAPI (300 nM; Sigma-Aldrich) was added for nuclear counter-staining in some slices. Imaging was done using a two-photon microscope (Olympus
Optical) with $20 \times$ water-immersion objective. For cell counts, the pyramidal layer of CA1 was centered on the $y$-axis of the microscopic field. The $x$-coordinates of the field were determined by centering an imaginary line perpendicular to the pyramidal layer that passed through the middle of the superior blade of dentate gyrus. Ten serial $x y$ planes images with best intensities were acquired at 2 $\mu \mathrm{m}$ vertical $(z)$ intervals in the CA1 subfield. Cell counting for $\mathrm{NeuN}(+)$ or lba-1(+) was performed in Z-stack images from whole microscopic field using ImageJ software.

\section{Lactate and LDH assays of clodronate effects}

Organotypic hippocampal slice cultures from C57BL/6 mice were cultured in poly-D-lysine-coated six-well tissue culture plates. Three slices were treated with clodronateencapsulated liposome (final concentration: $0.2 \mathrm{mg} / \mathrm{ml}$ ) and three slices were treated with an equal concentration of empty liposome from DIV0-6. All six slices were prepared from the same animal. Following a thorough washout on DIV6, culture medium with PBS was applied to both groups of slices from DIV6 to DIV28. Culture media were collected and changed biweekly. Images of all slices were obtained at media changes via brightfield microscopy with an Olympus CKX41 inverted microscope. Lactate was used as a biomarker of ictal activity (Berdichevsky et al. 2013) and lactate dehydrogenase $(\mathrm{LDH})$ concentrations were used as an assay of cell death (Berdichevsky et al. 2012), measured in spent culture medium collected during the biweekly media changes.

\section{Statistical analyses}

All values are expressed as mean \pm SEM. Statistical significance were evaluated with Student $t$ tests without or with Sidak correction for multiple comparisons where indicated, Fisher's exact test, or one-way/two-way ANOVA as indicated. Alpha $p$ value $<0.05$ is considered to be significantly different.

\section{Results}

\section{Clodronate depletes microglia in organotypic slices}

The concentration and duration of clodronate treatment in organotypic slices was optimized to obtain maximal microglial depletion. An equal concentration of empty liposomes was used as the control condition in all experiments utilizing clodronate. When clodronate (final con- 
Table 2. Statistical table

\begin{tabular}{llll}
\hline & Data structure & Type of test & Power \\
a & Normally distributed & $t$ test & 0.004 \\
b & Normally distributed & $t$ test & 0.001 \\
c & Normally distributed & $t$ test & 0.77 \\
d & Categorical & Fisher's exact test & 0.07 \\
e & Normally distributed & One-way ANOVA & 0.02 \\
f & Normally distributed & One-way ANOVA & 0.11 \\
g & Normal distributed & One-way ANOVA & 0.14 \\
h & Categorical & Fisher's exact test & 0.24 \\
i & Categorical & Fisher's exact test & 0.52 \\
j & Categorical & Fisher's exact test & 0.60 \\
k & Normally distributed & Two-way ANOVA & 0.39 for frequency, 0.46 for total duration, and 0.30 for mean duration \\
l & Normally distributed & One-way ANOVA & 0.31 \\
m & Normally distributed & One-way ANOVA & 0.36 \\
n & Normally distributed & One-way ANOVA & 0.56 \\
o & Normally distributed & One-way ANOVA & 0.99 \\
p & Normally distributed & One-way ANOVA & 0.89 \\
q & Normally distributed & One-way ANOVA & 0.62 \\
r & Normally distributed & $t$ test & 0.003 \\
s & Normally distributed & $t$ test & 0.01 \\
t & Categorical & Fisher's exact test & 0.36 \\
u & Normally distributed & One-way ANOVA & 0.54 \\
v & Normally distributed & One-way ANOVA & 0.051 \\
W* & Normally distributed & $t$ test with Sidak correction & $0.02,0.42,0.08,0.07,0.09,0.08,0.08$, and 0.13 at each time point \\
X* & Normally distributed & $t$ test with Sidak correction & $0.10,0.02,0.001,0.002,0.002,0.002,0.007,0.01$ at each time point \\
& & & \\
\hline
\end{tabular}

$* \alpha_{\mathrm{SID}}=1-(1-\alpha)^{1 / m}, \alpha=0.05, m=1,2,3,4,5,6,7,8 . \alpha_{\mathrm{SID}(\mathrm{MAX})}=0.06$

centration of $0.2 \mathrm{mg} / \mathrm{ml}$ in the culture media) was applied for $3 \mathrm{~d}$ to rat slices from DIV16 to DIV19, the number of microglia counted in the CA1 subfield decreased by $70.4 \%(95.5 \pm 10.9$ vs $28.25 \pm 9.8$ per field; $n=4 ; p=$ $0.004^{a}$; Table 2; Fig. $1 B$ ). The remaining microglia were small and rounded in shape, and had few ramified processes (Fig. 1A). To increase microglial depletion, the duration of treatment was extended up to $6 \mathrm{~d}$ (DIV16-DIV22). This reduced microglia by $96.2 \%$ (91.8 \pm 15.5 vs $3.5 \pm 3.2 ; n=4 ; p=0.001^{\mathrm{b}}$; Fig. $1 B$ ) compared to controls. The number of Iba-1(-) cells was not different between groups $(320.3 \pm 8.6$ per field in clodronate group vs $325.5 \pm 10.3$ per field in control group, $n=4, p=$ $0.77^{\mathrm{C}}$ ). The number of CA1 microglia in control slices treated with empty liposomes was not different from slices treated with an equal volume of PBS. Following clodronate depletion, microglia were not regenerated even after 3 weeks in culture (Fig. 1C), indicating that clodronate also effectively eliminated microglial progenitor cells.

\section{Microglial depletion has no anticonvulsant effects in rat slices}

We compared spontaneous SLAs at DIV22 according to the presence or absence of microglia ( $n=11$ each group). Equal numbers of slices from each animal were allocated to clodronate or control groups. Extracellular field potentials were recorded for $1 \mathrm{~h}$ in each slice. All slices showed at least one SLA in the microglia-depleted group and only $72.7 \%$ showed SLA in the control group ( $p=0.07^{\mathrm{d}}$; Fig. $2 C)$. The frequency of SLA in microglia-depleted slices was significantly higher than control $(13.3 \pm 3.1$ vs $3.9 \pm$ 2.1 SLA/h; $p=0.02^{\mathrm{e}}$; Fig. $\left.2 D\right)$. Total duration (13.4 \pm 4.1 vs $4.3 \pm 3.5 \min ; p=0.11^{\mathrm{f}}$; Fig. $2 E$ ) and mean duration of each SLA $\left(2.1 \pm 0.9\right.$ vs $0.5 \pm 0.2 \mathrm{~min} ; p=0.14^{\mathrm{g}}$; Fig. $\left.2 F\right)$ were longer in microglia-depleted slices than control, but the differences did not reach statistical significance.

\section{Microglial depletion has no antiepileptogenic effects in rat slices}

The preceding experiments indicate that microglial depletion had no anticonvulsant effect on seizure activity in cultured slices in which epilepsy was established. To evaluate the role of microglia on epileptogenesis, we applied clodronate before the onset of seizures, that is, from the beginning of culture (DIV0) to DIV6. In the organotypic hippocampal slice model, this time period is considered as the "latent" period, i.e. the time between brain injury and the development of spontaneous seizure activity (Berdichevsky et al., 2012). Following microglial depletion, field potentials were recorded at DIV6, 12, and 22 (Fig. $3 A$ ). SLAs were observed in $83.3 \%$ (vs $50 \%$ in control, $n$ $=6$ each group, $p=0.24^{\mathrm{h}}$ ), $83.3 \%$ (vs $66.7 \%$ in control, $n=6$ each group, $p=0.52$ ), and $37.5 \%$ (vs $25.0 \%$ in control, $n=8$ each group, $p=0.60^{\circ}$ ) in microglia-depleted slices on recoding at DIV6, 12 , and 22, respectively. Overall, the proportions of epileptic slices, which were defined as having more than one seizure during the observation time, were not statistically different between the microglia-depleted and control groups (Fig. 3B). The values for SLA frequency, duty cycle, and duration are listed in Table 3. On recording at DIV6 and 22, there were no significant differences in these parameters between microglia-depleted and control slices. These three parameters tended to be increased in microglia-depleted slices at DIV12, but the differences did not reach significance 
A

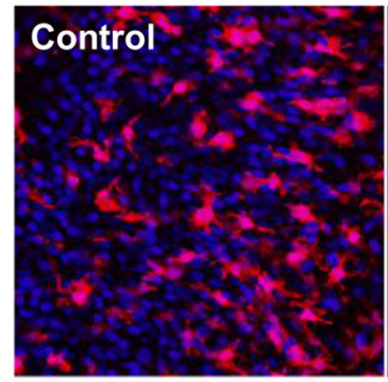

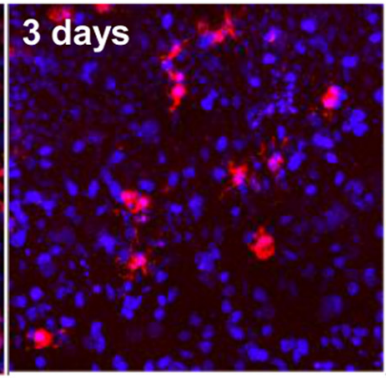

Iba-1 DAPI

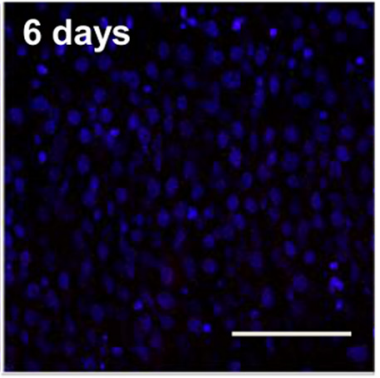

B

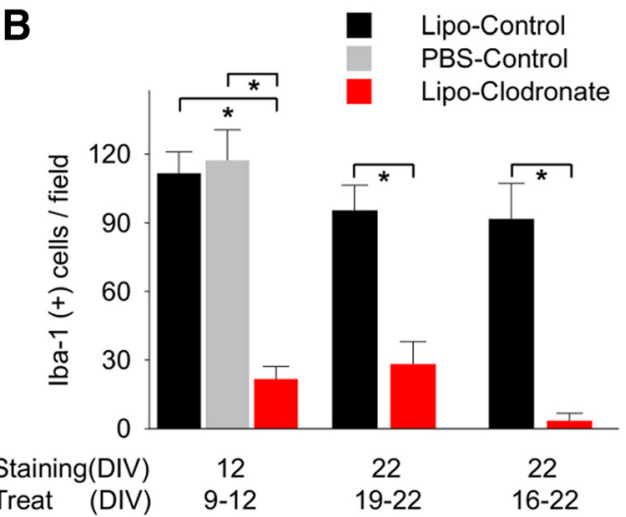

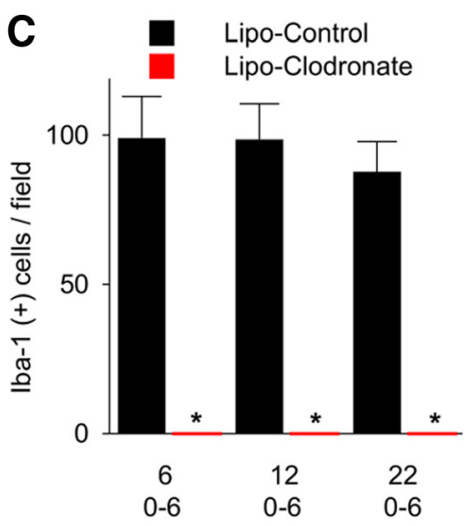

Figure 1. Elimination of microglia using liposomal (Lipo) clodronate from organotypic hippocampal slices of rat. $\boldsymbol{A}$, Iba-1-positive cells (microglia and macrophages) in CA1 were depleted by using liposomal clodronate $(0.2 \mathrm{mg} / \mathrm{ml})$. $\boldsymbol{B}$, Treatment for $3 \mathrm{~d}$ (from DIV9 to 12 ) decreased the number of microglia comparing liposome-control group and saline control group. Six day treatment from DIV16 to DIV22 eliminated more Iba-1(+) cells than $3 \mathrm{~d}$ treatment $(96.2 \%$ vs $70.4 \%, n=4$ per group, $p=0.07)$. $\boldsymbol{C}$, Microglial depletion persisted $16 \mathrm{~d}$ after washout. All values are expressed as mean \pm SEM. $* p<0.05$. Scale bar, $100 \mu \mathrm{m}$.

between the groups (Fig. 3C-E). Overall, there were no statistical differences between groups or ages ${ }^{k}$.

\section{Microglial depletion has no anticonvulsant or antiepileptogenic effects in mice}

Organotypic slices from wild-type C57BL/6 mice usually demonstrated more frequent SLA compared with agematched rat slices. To test the generalizability of the results from rat slices, we repeated the experiments described above in murine hippocampal slice cultures. Depletion of microglia by clodronate exposure from DIV0 and 6 did not alter spontaneous SLAs recorded at DIV6 (Fig. 4A). SLA frequency was $12.5 \pm 2.3$ per hour in microglia-depleted slices $(n=4)$ and $10.8 \pm 1.9$ per hour in control slices $(n=5)\left(p=0.31^{1}\right)$. Other parameterstotal duration $\left(5.0 \pm 0.7 \mathrm{~min}\right.$ vs $\left.4.3 \pm 1.2 \mathrm{~min} ; p=0.36^{\mathrm{m}}\right)$ and mean duration $(24.6 \pm 1.3 \mathrm{~s}$ vs $24.3 \pm 5.9 \mathrm{~s} ; p=$ $0.56^{\mathrm{n}}$ )-in microglia-depleted slices were also similar to control. Next, we applied clodronate from DIV6 to DIV12 and recorded at DIV12 to assess the effect of microglial depletion on ictogenesis. The frequency was $12.0 \pm 5.2$ per hour for microglia-depleted $(n=4)$ and $9.7 \pm 3.1$ per hour for control $(n=6)\left(p=0.99^{\circ}\right)$. Total SLA duration and mean SLA duration were $8.0 \pm 2.9 \mathrm{~min}, 37.8 \pm 11.3 \mathrm{~s}$ for microglia-depleted and $5.9 \pm 1.9 \mathrm{~min}, 53.7 \pm 23.8 \mathrm{~s}$ for control, respectively, and these differences were not statistically significant $\left(p=0.89^{p}\right.$ for total duration, $p=0.62^{q}$ for mean duration). We conclude that microglial depletion at these time periods in murine organotypic hippocampal slice cultures do not alter epileptogenesis or ictogenesis.

\section{Epileptogenesis is not dependent on T lymphocytes and/or microglia}

$\mathrm{T}$ lymphocytes are a part of the adaptive immune system that play an important role in activating the innate immune, i.e. inflammatory system, of the brain (Ransohoff and Brown, 2012) and have been hypothesized to contribute to epileptogenesis (Fabene et al. 2008; Marchi et al., 2011). To investigate the role of this cellular component of the immune system on epilepsy more precisely, we compared wild-type organotypic slices to organotypic slices depleted of either T lymphocytes or both microglia and $T$ lymphocytes by treating slices prepared from nude mice with clodronate $(0.02 \mathrm{mg} / \mathrm{ml})$. The numbers of $\mathrm{mi}$ croglia were counted in area CA1 in the three different preparations (slice cultures from wild-type (WT), nude (T lymphocyte-deficient) mice, and slices from nude mice treated with clodronate, $n=5-6$ each group). Nude mice showed fewer microglia per field $\left(p=0.003^{r}\right.$ vs rat, $p=$ $0.01^{\mathrm{s}}$ vs WT mouse; Fig. $5 A$ ). However, there was no correlation between the density of microglia and the incidence of epileptic slices across species (Fig. 5A). In mice, a lower concentration $(0.02 \mathrm{mg} / \mathrm{ml})$ of clodronate eliminated microglia as effectively as the higher concentration 


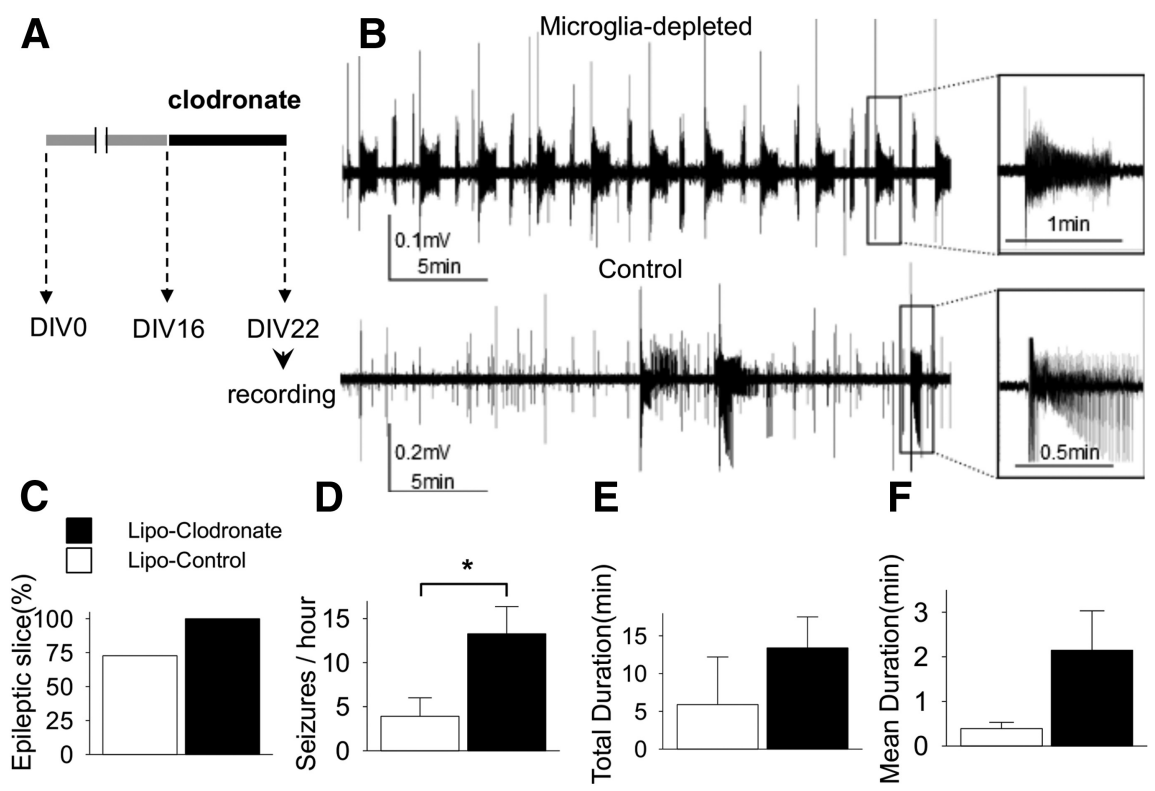

Figure 2. Effect of microglial depletion on ictogenesis in cultured rat slices. $\boldsymbol{A}$, Schematic drawing of experiment protocol. $\boldsymbol{B}$, Representative traces of field potentials recorded at DIV22 show that the microglia-depleted slice had more frequent and longer seizure-like activities compared to the control slice. $\boldsymbol{C}$, Bar graphs indicate the percentage of slices with more than one seizure-like activity during observation period in each group. $\boldsymbol{D}-\boldsymbol{F}$, The frequency of seizure-like activities was significantly greater in the microglia-depleted group $(13.3 \pm 3.1$ vs $3.9 \pm 2.1 / \mathrm{h}, n=11$ per group, $p=0.02)$. All values are expressed as mean $\pm \mathrm{SEM}, * p<$ 0.05 .

used in rat slices $(0.2 \mathrm{mg} / \mathrm{ml})$, so we used the lower concentration in the following experiments. Clodronate at $0.02 \mathrm{mg} / \mathrm{ml}$ did not alter neuronal populations (Fig. 5C,D).
Epileptogenesis proceeded at a similar rate in clodronatetreated nude mouse slices as in control slices. Recordings at DIV12 demonstrated SLAs in $40.0 \%$ of double-deficient
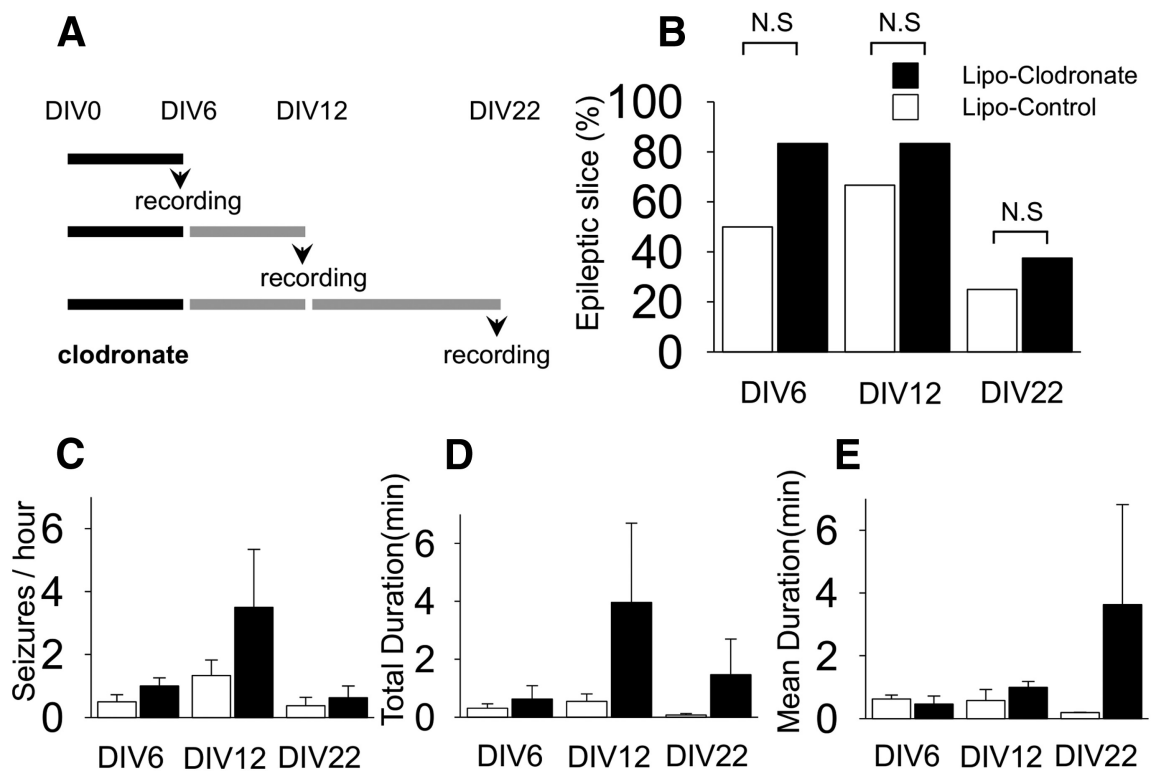

Figure 3. Effect of microglial depletion on epileptogenesis in cultured rat slices. $\boldsymbol{A}$, Liposomal (Lipo) clodronate or liposome-control was exposed to slices from DIV0 to 6 and spontaneous seizure-like activities were recorded at DIV6, 12 , or 22 according to the indicated protocols. $\boldsymbol{B}$, The proportions of slices demonstrating seizure-like activity during recording were not different between microglia-negative group and control group ( $n=6-8$ per group, $p=0.24,0.52$, and 0.60. respectively). $\boldsymbol{C}-\boldsymbol{E}$, Seizure frequency, total recorded seizure time, and mean seizure duration tend to be higher in slices depleted of microglia, although none of these differences were statistically different $(n=6-8$ per group, $p=0.24,0.30$, and 0.28 , respectively). N.S, Not significant. All values are expressed as mean \pm SEM. 
Table 3. Comparison of seizure-like activities between microglia-depleted and control slices

\begin{tabular}{llll}
\hline & Microglia-depleted & Control & $p$ value \\
Recording at DIV6 & & & \\
Frequency (SLA/h) & $1.0 \pm 0.3$ & $0.5 \pm 0.2$ & 0.17 \\
Total duration (s/h) & $37.7 \pm 27.7$ & $18.7 \pm 9.0$ & 0.53 \\
Mean duration (s) & $27.7 \pm 15.3$ & $37.3 \pm 7.7$ & 0.67 \\
Recording at DIV12 & & & \\
Frequency (SLA/h) & $3.5 \pm 1.8$ & $1.3 \pm 0.5$ & 0.24 \\
Total duration (s/h) & $237.7 \pm 164.2$ & $32.8 \pm 15.3$ & 0.30 \\
Mean duration (s) & $59.6 \pm 11.1$ & $34.5 \pm 20.9$ & 0.28 \\
Recording at DIV22 & & & \\
Frequency (SLA/h) & $0.6 \pm 0.4$ & $0.4 \pm 0.3$ & 0.59 \\
Total duration (s/h) & $88.0 \pm 73.8$ & $4.4 \pm 3.1$ & 0.28 \\
Mean duration (s) & $217.8 \pm 191.1$ & $11.5 \pm 0.5$ & 0.46 \\
\hline & & & \\
\hline
\end{tabular}

slices $(n=10)$ versus $62.5 \%$ in control slices prepared from nude mice $(n=8)\left(p=0.36^{t}\right)$. Analysis of seizure parameters (Fig. $5 E$ ) revealed that the total duration of SLAs in clodronate-treated nude mouse slices was not different from that of control slices $(20.0 \pm 12.0 \mathrm{~s}$ vs 33.1 $\left.\pm 18.4 \mathrm{~s} ; p=0.54^{\mathrm{u}}\right)$. SLAs were rarely observed in both groups. However, the frequency of SLAs in the double- deficient preparations was decreased compared to controls $\left(0.5 \pm 0.2 \mathrm{SLAs} / \mathrm{h}\right.$ vs $\left.1.6 \pm 0.5 \mathrm{SLAs} / \mathrm{h} ; p=0.051^{\mathrm{v}}\right)$. Thus, we conclude that epileptogenesis is not dependent on T lymphocytes and/or microglia in this model.

The time course of epileptogenesis and ictal cell death are not altered by the absence of microglia As epileptogenesis progresses in organotypic slices, more SLAs are generated (Dyhrfjeld-Johnsen et al., 2010), and just as in human epilepsy (Lazeyras et al., 2000; Canas et al., 2010), the increased epileptiform activity is associated with increases in local lactate (Berdichevsky et al., 2013). Ictal excitotoxic neuronal injury releases the cytoplasmic LDH to the culture media (Berdichevsky et al., 2012, 2013). To be certain that we had not missed a critical compensation that normalized epileptogenesis in the slices depleted of microglia, we used the lactate and LDH assays to follow the detailed time course of epileptogenesis in vitro. Mouse hippocampal slices were exposed to clodronate $(0.2 \mathrm{mg} / \mathrm{ml}$ ) at DIV0-6 (Fig. 6A,B), and lactate and LDH levels were assayed at each subsequent media change in three depleted versus three control slices from the same animal. Cumulative lactate production was slightly reduced in microglial-deficient slices (Fig.
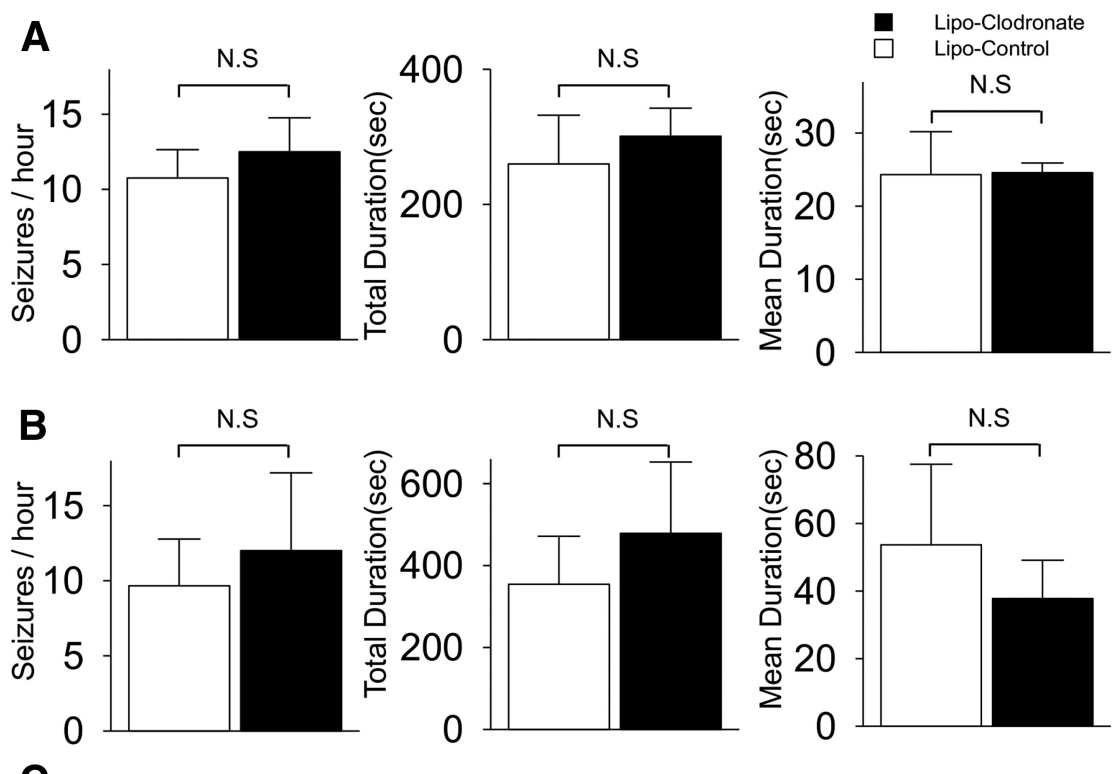

c

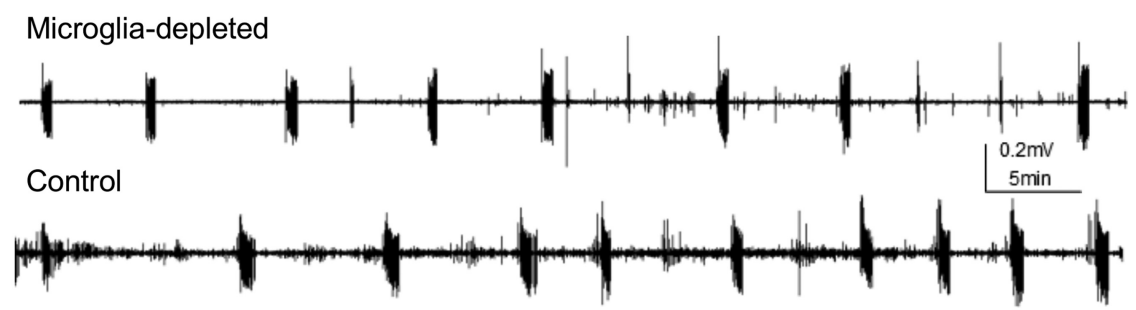

Figure 4. Effect of microglial depletion on epileptogenesis and ictogenesis in wild-type mice slices. $\boldsymbol{A}$, Data was recorded at DIV6 after exposure of liposome clodronate from DIV0 to 6. B, Data was recorded at DIV12 after exposure of liposomal clodronate from DIV6 to 12. Microglial depletion did not alter the frequency, total duration, or mean duration of seizure-like activities ( $n=4-5$ per group). C, Representative traces recorded at DIV6 from microglia-depleted and control group, shows similar patterns of spontaneous seizure-like activities. All values are expressed as mean \pm SEM. N.S, Not significant. 


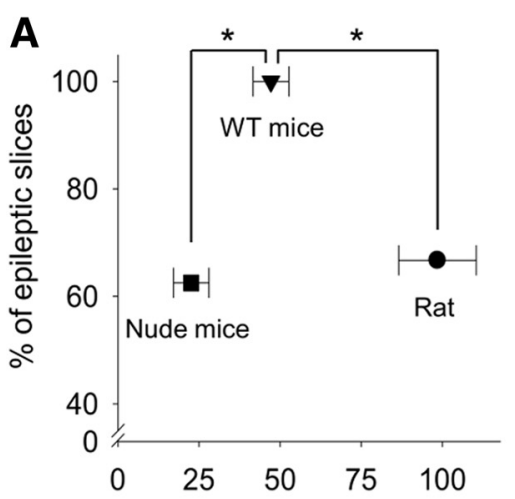

Number of Iba-1(+) cells per field

C

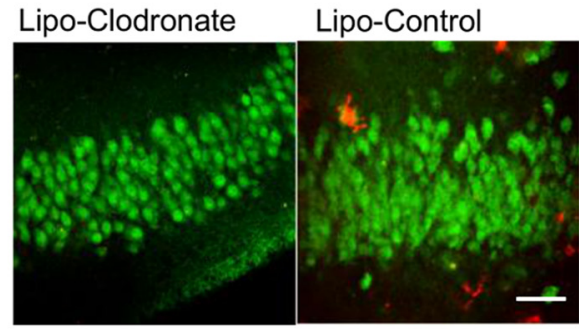

NeuN Iba-1

B

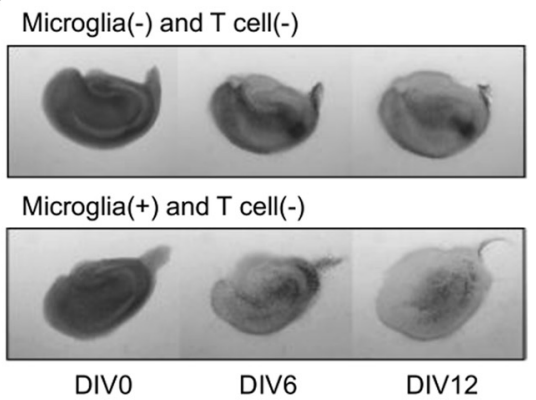

D
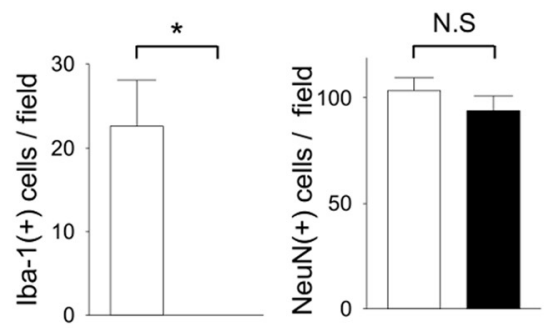

E
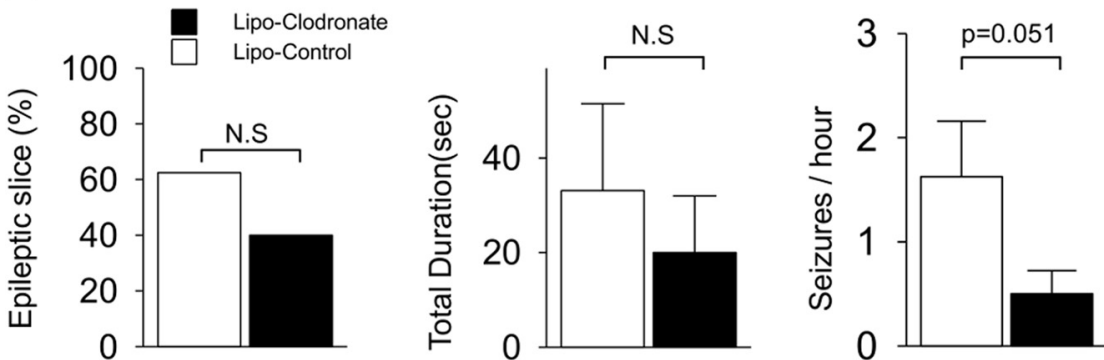

Figure 5. Microglial depletion from slices of nude mouse. $\boldsymbol{A}$, Comparison of the density of lba1-positive cells in area CA1 in control slices from different species ( $n=5-6$ per group) versus the percentage of slices that displayed seizure activity ( $n=5-8$ per group; different slices used for lba-1 staining and recording). Across species, there was no significant correlation between microglial density and fraction of epileptic slices $(R=-0.10, p=0.94)$. $B$, Examples of hippocampal cultures from nude mice at each time point. Liposomal (Lipo) clodronate (top, $0.02 \mathrm{mg} / \mathrm{ml}$ ) or liposome-control (bottom) was applied from DIV0 to 6. C, $\boldsymbol{D}$, Double immunostaining was performed with NeuN and Iba-1 antibodies. Quantification at CA1 reveals that liposomal clodronate did not affect the neuronal populations of nude mouse $(p=0.33)$, whereas it depleted all microglia ( $n=5$ per group). $\boldsymbol{E}$, The proportion of epileptic slices and total duration of seizure-like activities in microglia-depleted slices did not differ significantly from control slices, whereas the frequency of seizure-like activity was somewhat lower in microglia-depleted slices ( $n=8-10$ per group). All values are expressed as mean \pm SEM. $* p<0.05$; N.S, not significant. Scale bar, $100 \mu \mathrm{m}$.

$6 C)$, but this reduction was in line with the $10 \%$ reduction in total cell number due to microglial depletion (Benarroch, 2013), did not reach statistical significance ${ }^{\mathrm{w}}$ at any time point, and was much less than the lactate reduction during anticonvulsant treatment (Berdichevsky et al., 2012). Cumulative LDH release was increased early in the clodronate-treated slices (Fig. 6D), consistent with microglial cell death, but this difference was not sustained statistically ${ }^{x}$.

\section{Discussion}

In this in vitro study of post-traumatic epileptogenesis, electrophysiological recordings as well as lactate and
LDH assays were not significantly different in slices depleted of either microglia or both $T$ lymphocytes and microglia. We conclude that the systemic immune system, a compromised blood-brain barrier, and key cellular elements of the immune and inflammatory systems, including $T$ lymphocytes and microglia, are not necessary for epileptogenesis, at least in this in vitro model.

\section{Limitations}

This study utilized a well-characterized in vitro model of epileptogenesis, the rodent hippocampal organotypic slice preparation. Our goal was to test whether cellular effectors of inflammation were necessary elements of 
A
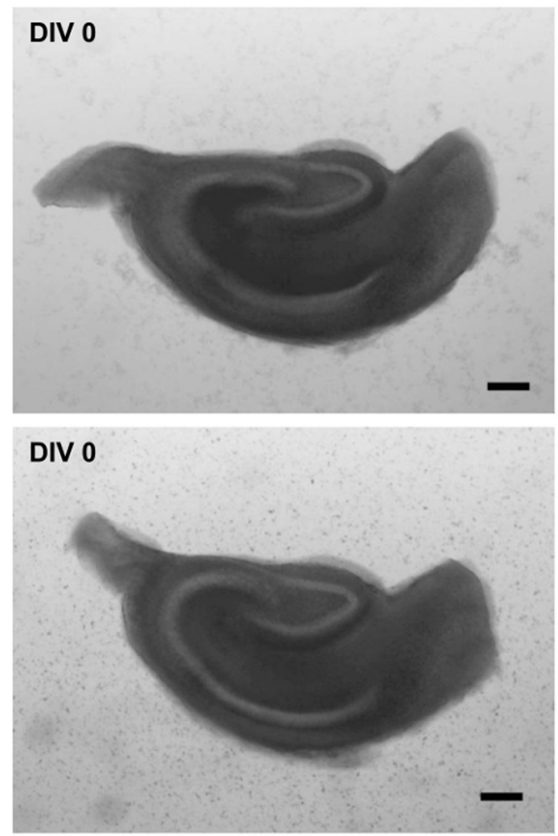

C

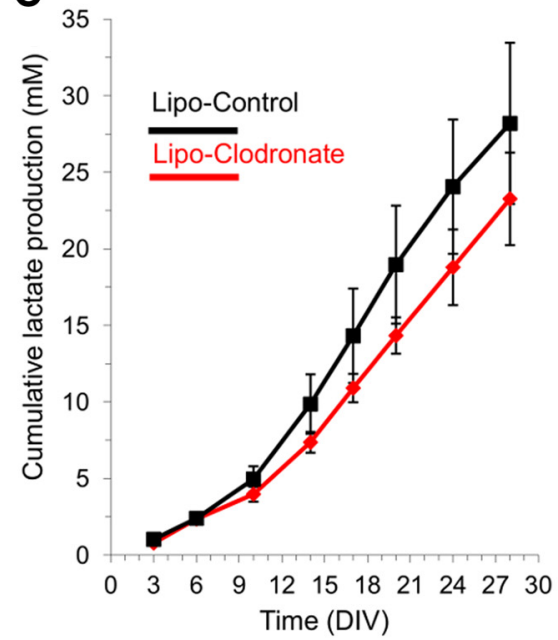

B
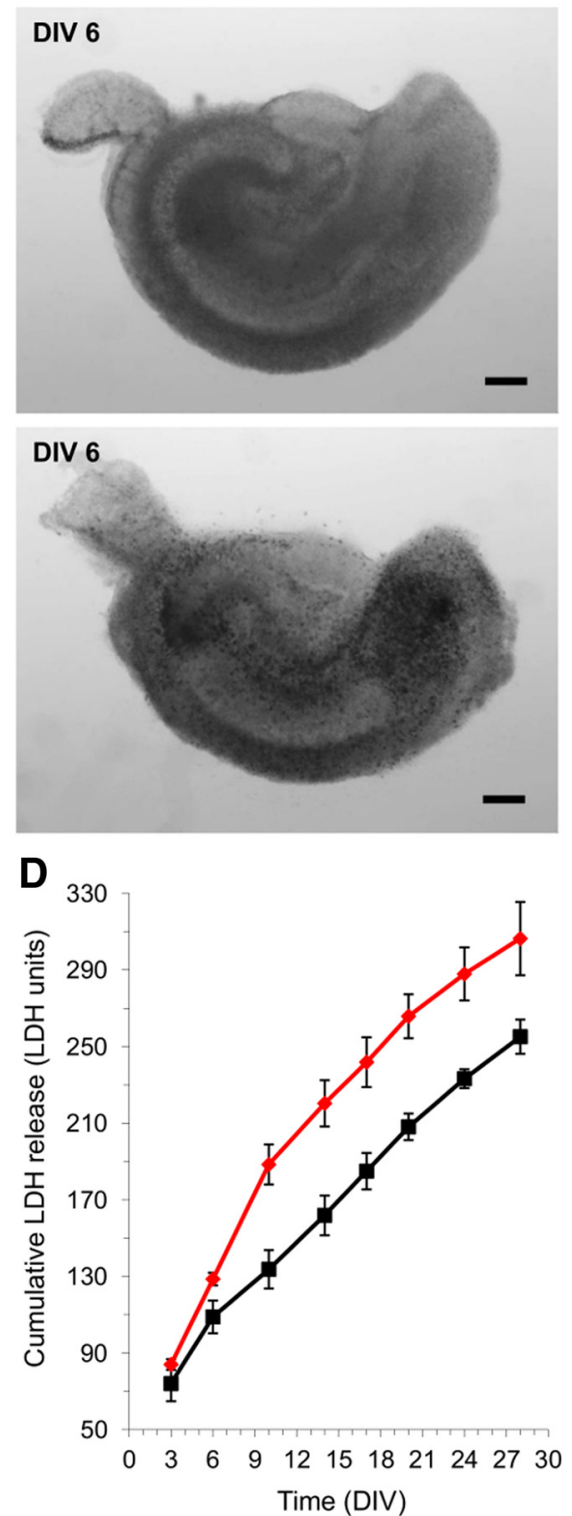

Figure 6. Long-term assays of epileptogenesis in microglia-depleted versus control hippocampal slice cultures. $\boldsymbol{A}$, Examples of slice culture brightfield micrographs at DIVO prior to clodronate treatment of upper slice. $\boldsymbol{B}$, Brightfield micrographs of the same slice cultures on DIV6 at the conclusion of clodronate treatment to the upper slice and empty liposome treatment of the lower slice. No deleterious effects of clodronate are evident at this magnification. $\boldsymbol{C}$, Cumulative group mean lactate production, assayed in the spent culture media at 3-4 daintervals during twice weekly media changes. $N=3$ slices each group; all slices from the same animal. $\boldsymbol{D}$, Cumulative group mean LDH release, assayed in the spent culture media. Same groups slices and media as for lactate assays in panel C. All values are expressed as mean \pm SEM. Scale bar, $250 \mu \mathrm{m}$.

epileptogenesis, so we did not attempt to quantify the number of $T$ lymphoctyes present in the slices from wild-type versus nude mice, nor did we attempt to quantify the relative effects of $T$ lymphocyte depletion on the rate of epileptogenesis. In this in vitro preparation, the control slices are also separated from the systemic immune system. Thus, we are not able to resolve whether epileptogenesis might proceed at a more rapid rate if systemic elements of the immune system were interacting across the blood-brain barrier
(Fabene et al., 2008). However, the cell loss (Berdichevsky et al., 2012), inflammatory reaction (degree of microglial activation in Fig. $1 A$ ), and rate of epileptogenesis (Dhyrfjeld-Johnesen et al., 2010; Berdichevsky et al., 2012) in the organotypic slice culture matches or exceeds what is observed in vivo (Tooyama et al., 2002; Ravizza et al., 2008; Williams et al., 2009; van Vliet et al., 2012), so there is no reason to expect that inflammation, epileptogenesis, or ictogenesis has been compromised in the control slices. 
The epileptic activity that develops in organotypic slices is severe: although SLA can be temporarily suppressed with phenytoin, SLA recrudesces after 3 weeks in culture (Berdichevsky et al., 2012). Although this recrudescence parallels human post-traumatic epilepsy (Temkin et al., 1990; Temkin, 2009), it is possible that a less severe epilepsy model would reveal modulatory effects of immunity or inflammation more readily than the organotypic slice culture model. Thus, we cannot conclude from these experiments that the immune and inflammatory systems are not involved in all epileptogeneses, but only that key cellular elements of these systems are not necessary for post-traumatic epileptogenesis, and that so far, this has only been demonstrated in vitro.

We did observe differences in epileptogenesis between murine slices from C57BL/6 mice (Fig. 4) versus slice cultures from nude mice (Fig. 5). However, inbred mouse strains have variable rates of epileptogenesis (Papandrea et al., 2009), wild-type controls are not available for nude mice, and epileptogenesis in slices from nude mice were comparable to slices from rats (Fig. 5A). Thus, we can deduce that epileptogenesis proceeds in the absence of $T$ lymphocytes, but we cannot make conclusions regarding potential influences of $T$ lymphocytes on the rate of epileptogenesis. Overall, there was no correlation between microglial counts and the fraction of epileptic slices across species (Fig. 5A). In slices from animals other than nude mice, the increased seizure frequency after microglia depletion may reflect the neuroprotective actions of microglia (Mosser and Edwards, 2008; Smith et al., 2012; Benarroch, 2013), although the magnitude of effects were not consistent between strains and species. These minor differences in epileptogenesis do not diminish the importance of the central finding that slices without cellular mediators of inflammation exhibit robust epileptogenesis. This implies that the full inflammatory cascade cannot be a necessary component of all forms of epileptogenesis.

Because microglia were progressively eliminated from 0 to $6 \mathrm{~d}$ after trauma, our experiments do not preclude a necessary but very early role for microglia in epileptogenesis. However, manipulation of inflammatory mediators during this interval are ineffective in vivo (Noe et al., 2013), indicating that if inflammation had a necessary role in epileptogenesis, it would extend beyond the phase during which the slice cultures still contained microglia.

Although in vitro experiments must be extrapolated with caution, it should also be born in mind that there is no feasible way to remove the blood-brain barrier, systemic immune system, and local cellular elements of the immune and inflammatory systems from current in vivo models.

\section{Implications}

Determining whether a particular system is involved in a mechanism of neural plasticity is complex. This issue has been reviewed in detail for the process of long-term potentiation of synaptic strength (Sanes and Lichtman, 1999). Obstacles to be overcome include the heterogeneity of the process of epileptogenesis. For example, Rasmussen's encephalitis or anti-NMDAR encephalitis seem unlikely to entail precisely the same molecular pathophysiology as post-traumatic epilepsy. Nevertheless, inflammation has been strongly implicated in prior studies of epilepsy associated with hippocampal sclerosis (Ravizza et al., 2008), which is not considered to be an immune-mediated injury. However, more recent studies have not supported a necessary role for inflammation in hippocampal sclerosis (Aalbers et al., 2014). Another problem is distinguishing whether a system modulates or mediates (i.e., is necessary for) a mechanism of plasticity. Mechanisms of plasticity that involve multiple large networks, each of which is comprised of many types of cells and synapses, are particularly prone to these interpretational difficulties.

The interpretation of experimental results is further complicated because some mediators of the inflammatory response are also involved in physiological neural plasticity. Thus, when these inflammatory mediators are blocked, the subsequent effects on epilepsy are often interpreted to be a consequence of the effects of the blockade on the inflammatory system. However, it is equally possible that the effects on epilepsy are a consequence of the blockade's interference with normal mechanisms of synaptic plasticity. This issue is more easily appreciated when considered for systems that are anatomically separated. For example, the gastrointestinal system is not considered to be a mediator of neural plasticity because of the effects of antagonists of vasoactive intestinal polypeptide or cholecystokinin on epileptogenesis (Dobolyi et al., 2014). The effects of IL-1 $\beta$, IL-6, and TNF $\alpha$ antagonists on epileptogenesis provide the same strength of evidence that the inflammatory system is a key mediator of epileptogenesis.

One approach to these interpretational difficulties is to remove as many of the "upstream" elements of inflammation as possible and measure the effects on epileptogenesis. Based on our observations using the in vitro organotypic hippocampal slice culture model of posttraumatic epileptogenesis, cellular elements of the immune and inflammatory systems were not necessary for epileptogenesis. We look forward to other laboratories' dissection of this problem in vivo and in vitro, including focused genetic deletion experiments with wild-type littermate controls. Because microglia are considered to be the final common phagocytic pathway of the brain's inflammatory response (Schafer et al., 2013), we did not extend these experiments to consider the effects of antagonists of individual chemical mediators of the inflammatory response. Such experiments would be difficult to interpret for the reasons described above. Thus, the immune and inflammatory systems may modulate, but do not mediate, at least some forms of epileptogenesis.

In the epilepsy syndromes in which the involvement of the immune and inflammatory systems appear more obvious, such as Rasmussen's encephalitis and NMDAR antibody encephalitis, we do not yet know whether the ongoing activity of these systems is necessary, or whether they are involved in a temporally restricted number of stages of epileptogenesis, and are not subsequently necessary once those stages are complete. For 
example, in Rasmussen's encephalitis, anti-inflammatory therapy is ineffective (Freeman, 2005), indicating that at some point in the process of epileptogenesis, epilepsy becomes independent of the inflammatory system. In contrast, NMDAR antibody encephalitis is often responsive to immune therapy (Titulaer et al., 2013).

In light of the current results and the effects of antiinflammatory and immune therapies on human and experimental epilepsies, the role of inflammatory mediators in epilepsy can be interpreted in three ways. First, there are mechanisms of epileptogenesis that are independent of the immune and inflammatory systems, as demonstrated here. Second, there are epilepsy syndromes for which the immune and/or inflammatory system may be a necessary component of at least some stages of epileptogenesis, although direct evidence for this has not yet been developed. Third, the inflammatory system may not contribute directly to epileptogenesis, but manipulation of the shared mediators of synaptic plasticity and inflammation may produce beneficial anticonvulsant or antiepileptogenic effects.

\section{Future directions}

Developing simplified in vitro models of epilepsy syndromes in which the immune system is suspected to play a central role, such as NMDAR antibody encephalitis, will permit further testing of the role of immunity in epilepsy. Such studies might address a question raised by the current results: if inflammation is not necessary for epileptogenesis, does it nevertheless accelerate or otherwise modulate epileptogenesis? Regardless of the role of the inflammatory system in epilepsy, it will be important to pursue the anticonvulsant and antiepileptogenic effects of the antagonists of shared mediators of inflammation and synaptic plasticity, including cyclooxygenase products, $\mathrm{IL}-1 \beta$, IL-6, and TNF $\alpha$.

\section{References}

Aalbers MW, Rijkers K, Majoie HJ, Dings JT, Schijns OE, Schipper S, De Baets MH, Kessels A, Vles JS, Hoogland G. (2014) The influence of neuropathology on brain inflammation in human and experimental temporal lobe epilepsy. J Neuroimmunol 271:36-42.

Albus K, Heinemann U, Kovács R (2013) Network activity in hippocampal slice cultures revealed by long-term in vitro recordings. J Neurosci Methods 217:1-8.

Balschun D, Wetzel W, Del Rey A, Pitossi F, Schneider H, Zuschratter W, Besedovsky HO (2004) Interleukin-6: a cytokine to forget. FASEB J 18:1788-1790. CrossRef Medline

Bausch SB, McNamara JO (2000) Synaptic connections from multiple subfields contribute to granule cell hyperexcitability in hippocampal slice cultures. J Neurophysiol 84:2918-2932. Medline

Benarroch EE (2013) Microglia: multiple roles in surveillance, circuit shaping, and response to injury. Neurology 81:1079-1088. CrossRef Medline

Berdichevsky Y, Dzhala V, Mail M, Staley KJ (2012) Interictal spikes, seizures and ictal cell death are not necessary for post-traumatic epileptogenesis in vitro. Neurobiol Dis 45:774-785. CrossRef Medline

Berdichevsky Y, Dryer AM, Saponjian Y, Mahoney MM, Pimentel CA, Lucini CA, Usenovic M, Staley KJ (2013) PI3K-Akt signaling activates mTOR-mediated epileptogenesis in organotypic hippocampal culture model of post-traumatic epilepsy. J Neurosci 33:90569067. CrossRef Medline
Bien CG, Bauer J, Deckwerth TL, Wiendl H, Deckert M, Wiestler OD, Schramm J, Elger CE, Lassmann H (2002) Destruction of neurons by cytotoxic T cells: a new pathogenic mechanism in Rasmussen's encephalitis. Ann Neurol 51:311-318. Medline

Canas N, Soares P, Calado S, Pestana R, Ribeiro C, Vale J (2010) Pathophysiology and long-term outcome of reversible tumor-like lesions induced by presenting status epilepticus. J Neuroimaging 20:169-174. CrossRef Medline

Davis R, Dalmau J (2013) Autoimmunity, seizures, and status epilepticus. Epilepsia 54[Suppl 6]:46-49. CrossRef

Dobolyi A, Kékesi KA, Juhász G, Székely AD, Lovas G, Kovács Z (2014) Receptors of peptides as therapeutic targets in epilepsy research. Curr Med Chem 21:764-787 Medline

Dudek FE, Staley KJ (2012) The time course and circuit mechanisms of acquired epileptogenesis. In: Jasper's basic mechanisms of the epilepsies, 4th edition (Noebels JL, Avoli M, Rogawski MA, Olsen RW, Delgado-Escueta AV, eds.). Bethesda, MD: National Center for Biotechnology Information.

Dyhrfjeld-Johnsen J, Berdichevsky Y, Swiercz W, Sabolek H, Staley KJ (2010) Interictal spikes precede ictal discharges in an organotypic hippocampal slice culture model of epileptogenesis $\mathrm{J}$ Clin Neurophysiol 27:418-424. CrossRef Medline

Fabene PF, Navarro Mora G, Martinello M, Rossi B, Merigo F, Ottoboni L, Bach S, Angiari S, Benati D, Chakir A, Zanetti L, Schio F, Osculati A, Marzola P, Nicolato E, Homeister JW, Xia L, Lowe JB, McEver RP, Osculati F, et al (2008) A role for leukocyteendothelial adhesion mechanisms in epilepsy. Nat Med 14:13771383. CrossRef Medline

Freeman JM (2005) Rasmussen's syndrome: progressive autoimmune multi-focal encephalopathy. Pediatr Neurol 32:295-299. CrossRef Medline

Granata T, Andermann F (2013) Rasmussen encephalitis. Handb Clin Neurol 111:511-519. CrossRef Medline

Gresa-Arribas N, Titulaer MJ, Torrents A, Aguilar E, McCracken L, Leypoldt F, Gleichman AJ, Balice-Gordon R, Rosenfeld MR, Lynch D, Graus F, Dalmau J (2014) Antibody titres at diagnosis and during follow-up of anti-NMDA receptor encephalitis: a retrospective study. Lancet Neurol 13:167-177. CrossRef Medline

Grøndahl TO, Langmoen IA (1993) Epileptogenic effect of antibiotic drugs. J Neurosurg 78:938-43. CrossRef Medline

Gutnick MJ, Wolfson B, Baldino F Jr (1989) Synchronized neuronal activities in neocortical explant cultures. Exp Brain Res 76:131-40. Medline

Kohl A, Dehghani F, Korf HW, Hailer NP (2003) The bisphosphonate clodronate depletes microglial cells in excitotoxically injured organotypic hippocampal slice cultures. Exp Neurol 181:1-11. Medline

Khurgel M, Switzer RC 3rd, Teskey GC, Spiller AE, Racine RJ, Ivy GO (1995) Activation of astrocytes during epileptogenesis in the absence of neuronal degeneration. Neurobiol Dis 2:23-35. Medline

Kipnis J, Cohen H, Cardon M, Ziv Y, Schwartz M (2004) T cell deficiency leads to cognitive dysfunction: implications for therapeutic vaccination for schizophrenia and other psychiatric conditions. Proc Natl Acad Sci U S A 101:8180-8185. CrossRef Medline

Kumamaru H, Saiwai H, Kobayakawa K, Kubota K, van Rooijen N, Inoue K, Iwamoto Y, Okada S (2012) Liposomal clodronate selectively eliminates microglia from primary astrocyte cultures. J Neuroinflammation 9:116. CrossRef Medline

Lampron A, Elali A, Rivest S (2013) Innate immunity in the CNS: redefining the relationship between the CNS and Its environment. Neuron 78:214-232. CrossRef Medline

Lazeyras F, Blanke O, Zimine I, Delavelle J, Perrig SH, Seeck M (2000) MRI, (1)H-MRS, and functional MRI during and after prolonged nonconvulsive seizure activity. Neurology 55:1677-1682 Medline

Librizzi L, Noè F, Vezzani A, de Curtis M, Ravizza T (2012) Seizureinduced brain-borne inflammation sustains seizure recurrence and blood-brain barrier damage. Ann Neurol 72:82-90. CrossRef Medline 
Liimatainen S, Kai L, Johanna P, Tiina A, Jukka P (2013) Immunological perspectives of temporal lobe seizures. J Neuroimmunol 263:1-7. CrossRef Medline

Marchi N, Johnson AJ, Puvenna V, Johnson HL, Tierney W, Ghosh C, Cucullo L, Fabene PF, Janigro D (2011) Modulation of peripheral cytotoxic cells and ictogenesis in a model of seizures. Epilepsia 52:1627-1634.

McBain CJ, Boden P, Hill RG (1989) Rat hippocampal slices 'in vitro' display spontaneous epileptiform activity following long-term organotypic culture. J Neurosci Methods 27:35-49. Medline

Minami M, Kuraishi Y, Satoh M (1991) Effects of kainic acid on messenger RNA levels of IL-1 beta, IL-6,TNF alpha and LIF in the rat brain. Biochem Biophys Res Commun 176:593-598. Medline

Mosser DM, Edwards JP (2008) Exploring the full spectrum of macrophage activation. Nat Rev Immunol 8:958-969. CrossRef Medline

Noe FM, Polascheck N, Frigerio F, Bankstahl M, Ravizza T, Marchini S, Beltrame L, Banderó CR, Löscher W, Vezzani A (2013).Pharmacological blockade of IL- $1 \beta / \mathrm{IL}-1$ receptor type 1 axis during epileptogenesis provides neuroprotection in two rat models of temporal lobe epilepsy. Neurobiol Dis 59:183-193. CrossRef Medline

Paolicelli RC, Bolasco G, Pagani F, Maggi L, Scianni M, Panzanelli P, Giustetto M, Ferreira TA, Guiducci E, Dumas L, Ragozzino D, Gross CT (2011) Synaptic pruning by microglia is necessary for normal brain development. Science 333:1456-1458.

Papageorgiou IE, Fetani AF, Lewen A, Heinemann U, Kann O (2014) Widespread activation of microglial cells in the hippocampus of chronic epileptic rats correlates only partially with neurodegeneration. Brain Struct Funct. May 31. Epub. CrossRef Medline

Papandrea D, Kukol WS, Anderson TM, Herron BJ, Ferland RJ (2009) Analysis of flurothyl-induced myoclonus in inbred strains of mice. Epilepsy Res. 87:130-6.

Polfliet MM, Goede PH, van Kesteren-Hendrikx EM, van Rooijen N, Dijkstra CD, van den Berg TK (2001) A method for the selective depletion of perivascular and meningeal macrophages in the central nervous system. J Neuroimmunol. 116:188-95. Medline

Pribiag H, Stellwagen D (2014) Neuroimmune regulation of homeostatic synaptic plasticity. Neuropharmacology 78:13-22.

Ransohoff RM, Brown MA (2012) Innate immunity in the central nervous system. J Clin Invest 122:1164-1171. CrossRef Medline

Ransohoff RM, Cardona AE (2010) The myeloid cells of the central nervous system parenchyma. Nature 468:253-262. CrossRef Medline

Ravizza T, Gagliardi B, Noé F, Boer K, Aronica E, Vezzani A (2008) Innate and adaptive immunity during epileptogenesis and spontaneous seizures: evidence from experimental models and human temporal lobe epilepsy. Neurobiol Dis 29:142-160. CrossRef Medline

Sanes JR, Lichtman JW (1999) Can molecules explain long-term potentiation? Nat Neurosci 2:597-604. CrossRef Medline

Sasaki Y, Ohsawa K, Kanazawa H, Kohsaka S, Imai Y (2001) Iba1 is an actin-cross-linking protein in macrophages/microglia. Biochem Biophys Res Commun. 286:292-7. CrossRef Medline

Schafer DP, Lehrman EK, Kautzman AG, Koyama R, Mardinly AR, Yamasaki R, Ransohoff RM, Greenberg ME, Barres BA, Stevens B
(2012) Microglia sculpt postnatal neural circuits in an activity and complement-dependent manner. Neuron 74:691-705. CrossRef Medline

Schafer DP, Lehrman EK, Stevens B (2013) The "quad-partite" synapse: microglia-synapse interactions in the developing and mature CNS. Glia 61:4-36. CrossRef

Schneider H, Pitossi F, Balschun D, Wagner A, del Rey A, Besedovsky HO (1998) A neuromodulatory role of interleukin-1beta in the hippocampus. Proc Natl Acad Sci U S A 95:7778-7783. Medline

Smith JA, Das A, Ray SK, Banik NL (2012) Role of pro-inflammatory cytokines released from microglia in neurodegenerative diseases. Brain Res Bull 87:10-20. CrossRef Medline

Temkin NR (2009) Preventing and treating posttraumatic seizures: the human experience. Epilepsia 50[Suppl 2]:10-13. CrossRef

Temkin NR, Dikmen SS, Wilensky AJ, Keihm J, Chabal S, Winn HR (1990) A randomized, double-blind study of phenytoin for the prevention of post-traumatic seizures. N Engl J Med 323:497-502. CrossRef Medline

Titulaer MJ, McCracken L, Gabilondo I, Armangué T, Glaser C, lizuka T, Honig LS, Benseler SM, Kawachi I, Martinez-Hernandez E, Aguilar E, Gresa-Arribas N, Ryan-Florance N, Torrents A, Saiz A, Rosenfeld MR, Balice-Gordon R, Graus F, Dalmau J (2013) Treatment and prognostic factors for long-term outcome in patients with anti-NMDA receptor encephalitis: an observational cohort study. Lancet Neurol 12:157-165. CrossRef Medline

Tooyama I, Bellier JP, Park M, Minnasch P, Uemura S, Hisano T, Iwami M, Aimi Y, Yasuhara O, Kimura H (2002) Morphologic study of neuronal death, glial activation, and progenitor cell division in the hippocampus of rat models of epilepsy. Epilepsia 43[Suppl 9]:39-43. CrossRef

van Vliet EA, Forte G, Holtman L, den Burger JC, Sinjewel A, de Vries HE, Aronica E, Gorter JA (2012) Inhibition of mammalian target of rapamycin reduces epileptogenesis and blood-brain barrier leakage but not microglia activation. Epilepsia 53:1254-1263. CrossRef

Vezzani A, Conti M, De Luigi A, Ravizza T, Moneta D, Marchesi F, De Simoni MG (1999) Interleukin-1 beta immunoreactivity and microglia are enhanced in the rat hippocampus by focal kainate application: functional evidence for enhancement of electrographic seizures. J Neurosci 19:5054-5065.

Vezzani A, Balosso S, Ravizza T (2012) Inflammation and epilepsy. Handb Clin Neurol 107:163-175. CrossRef Medline

Vitkovic L, Bockaert J, Jacque C (2000) "Inflammatory" cytokines: neuromodulators in normal brain? J Neurochem 74:457-471. Medline

Williams PA, White AM, Clark S, Ferraro DJ, Swiercz W, Staley KJ, Dudek FE (2009) Development of spontaneous recurrent seizures after kainate-induced status epilepticus. J Neurosci 29, 21032112. CrossRef Medline

Yirmiya R, Winocur G, Goshen I (2002) Brain interleukin-1 is involved in spatial memory and passive avoidance conditioning. Neurobiol Learn Mem 78:379-389. Medline

Yirmiya R, Goshen I (2011) Immune modulation of learning, memory, neural plasticity and neurogenesis. Brain Behav Immun 25:181213. CrossRef Medline 